\title{
LX. A comparison of the lonization produced in gases by penetrating röntgen and radium rays
}

\section{A.S. Eve M.A.}

To cite this article: A.S. Eve M.A. (1904) LX. A comparison of the lonization produced in gases by penetrating röntgen and radium rays, Philosophical Magazine Series 6, 8:47, 610-618, DOI: 10.1080/14786440409463231

To link to this article: http://dx.doi.org/10.1080/14786440409463231

册 Published online: 08 Jun 2010.

Submit your article to this journal $[\pi$

Џ Article views: 3

Q View related articles $\square$

4 Citing articles: 2 View citing articles ๘ 
Fig. 3.-Intensity Curves for Primary Colours (Cireular Source 2థ=32').

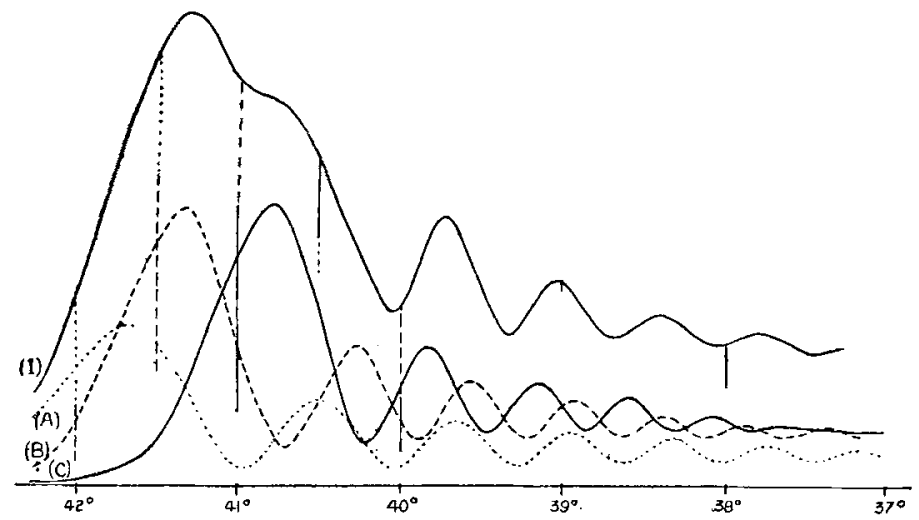

curve (A) represents value of $1.00 \mathrm{~F}\left(\frac{r^{j}}{\lambda}\right)^{\frac{1}{3}}$ for $\lambda=6302 \times 10-8 \mathrm{~cm} . r=0.025 \mathrm{~cm}$.

curve (B)

$162 F\left(\begin{array}{l}r^{\pi} \\ \lambda\end{array}\right)^{\frac{1}{3}}, \lambda=5211 \quad$,

curve (C)

$1 \cdot 60 \mathrm{~F}\left(\frac{r^{7}}{\lambda}\right)^{\frac{1}{3}}, \lambda=4659$,

- curve (I)

total intensity.

LX. A Comparison of the Ionization produced in Gases by penetrating Röntgen and Radium Rays. By A. S. EvE, M.A., Lecturer in Mathematics at McGill University, Montreal *

GVIDENCE is gradually aceumulating in favour of the 11 view that the $\gamma$ rays and Röntgen rays are identical in their nature. The case has been fully considered by Rutherford in 'Radioactivity,' pp. 141-146. The chief objection to the theory consisted in the wide divergence of the effects produced by the respective rays when ionizing various gases and vapours. The three types of rays from radium all produce ionization currents proportional to the densities of the gases through which the rays pass. The Röntgen rays have been found to diverge widely from this law.

The following table will furnish an example; it is an extract from a paper by Strutt, Proc. Roy. Soc. 5th Aug. 1903 :-

* Communicated by Prof. Rutherford, F.R.S. 
Gases by penetrating Röntgen and Radium Rays.

\begin{tabular}{|c|c|c|c|}
\hline Gas. & $\begin{array}{l}\text { Relative } \\
\text { Density. }\end{array}$ & $\gamma$ Rays. & $\begin{array}{c}\text { Röntgen } \\
\text { Rays. }\end{array}$ \\
\hline$\Lambda \operatorname{ir} \ldots$ & 1 & 1 & 1 \\
\hline $\mathrm{H}_{2} \mathrm{~S}$ & 1.2 & ... & 6 \\
\hline Chloroform & $4 \cdot 3$ & $4 \cdot 9$ & 32 \\
\hline Methyl Iodide ... & $5 \cdot 0$ & $4 \cdot 8$ & 72 \\
\hline
\end{tabular}

The values in the right column were found with soft rays, and it has been noted that the results obtained varied considerably with the type of bulb employed. Professor Rutherford suggested that the more penetrating rays from a hard bulb might give figures approximating to those obtained from $\dot{\gamma}$ rays. Some preliminary experiments confirmed this forecast, and a short account of them was forwarded to 'Nature,' 10th March, 1904, to which Rutherford added a letter on the theoretical explanation of the results.

Apparatus.

A large hard bulb was employed with a powerful induction-coiland Wehnelt interruptor.

Fig. I. Two electroscopes were placed at

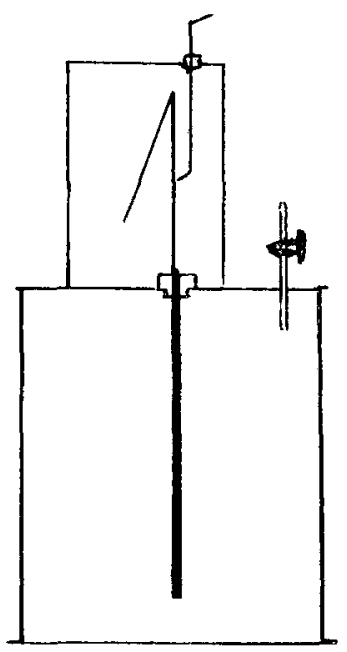
equal distances, about 60 cms., from the focus of the bulb. Each electroscope was completely covered by a removable lead vessel $1.7 \mathrm{~mm}$. in thickness. In the earlier experiments trouble was caused by some of the gases attacking the leaves of the electroscope. The apparatus used was therefore modified to the form shown in figs. 1 and 2. The lower vessels were brass cylinders with zinc ends, measuring $12 \mathrm{cms}$. in diameter, $13 \mathrm{cms}$. in height, and $1.8 \mathrm{~mm}$. in thickness. Brass rods along the axes of the cylinders were insulated by ebonite corks and passed upwards into small electroscopes, $5.5 \times 4 \times 9 \mathrm{cms}$. These were covered by lead pots $1.7 \mathrm{~mm}$. thick. The large and small lead covers were used whilst the bulb was running, and were removed in order to take the readings. The upper electroscopes were 
further screened from the direct rays from the focus of the bulb by a block of lead $4 \cdot 7 \mathrm{cms}$. thick.

Fig. 2.
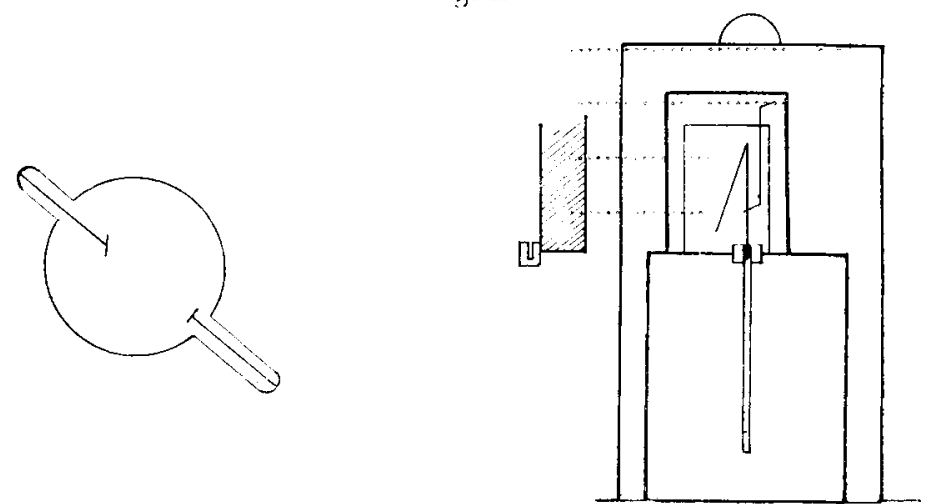

One of the brass cylinders was filled with air at barometric pressure, and served as a standard. The variations in the intensity of the rays from the bulb rendered such a standard necessary. The other cylinder was exhausted by a pump and filled with the required gas which passed through glasswool and phosphorus pentoxide. In working with the vapours of chloroform, carbon tetrachloride, and methyliodide, readings were taken at various pressures less than the vapour-densities. The natural leaks were deducted from the deflexions due to the ionization currents, and the readings of the exhausted electroscope were reduced to a percentage of those of the standard electroscope.

Arrangements were made to take observations of the values for the $\gamma$ rays. The radium was sealed in a glass tube placed in a hole in a cube of lead suspended behind the thick lead screen. The rays therefore passed through $1 \mathrm{~cm}$. of lead before reaching the lower large cylinders, and through more than $6 \mathrm{cms}$. in order to strike the small electroscope above. In the early experiments some irregularities were traced to convection currents caused by the heat from the electric lamps when the lead vessels were removed. The heat was screened by two sheets of plate-glass $6 \mathrm{~mm}$. thick and by a sheet of paper. The Röntgen rays therefore penetrated the walls of the bulb, 12 mms. of glass, 1.7 of lead, and 1.8 of brass. Care was taken to employ a saturating E.M.F.

\section{Röntgen Rays.}

The following table shows the values obtained in the present experiment as compared with those previously recorded for soft rays :- 
Gases by penetrating Röntgen and Rotdium Rays.

\begin{tabular}{|c|c|c|c|}
\hline Gas. & $\begin{array}{l}\text { Relative } \\
\text { Density. }\end{array}$ & $\begin{array}{c}\text { Previous } \\
\text { values. }\end{array}$ & $\begin{array}{c}\text { Present } \\
\text { values. }\end{array}$ \\
\hline $\mathrm{H}$ & 07 & $\cdot 11^{*}$ & $\cdot 42$ \\
\hline Air ........ & $1 \cdot 0$ & $1 \cdot 0$ & $1 \cdot 0$ \\
\hline $\mathrm{H}_{2} \mathrm{~S} \quad \ldots \ldots \ldots$ & $1 \cdot 2$ & 6 & $\cdot 9$ \\
\hline $\mathrm{SO}_{2}, \ldots \ldots \ldots \ldots \ldots \ldots \ldots \ldots \ldots \ldots \ldots \ldots \ldots \ldots \ldots \ldots \ldots$ & $2 \cdot 2$ & 8 & $2 \cdot 3$ \\
\hline Chloroform .... & $4: 3$ & 32 & 46 \\
\hline Carbon Tetrachloride ...... & $5 \cdot 3$ & 45 & $4 \cdot 9$ \\
\hline Methyl Iodide... & $5 \cdot 0$ & 72 & 135 \\
\hline
\end{tabular}

* Strutt $\cdot 11$; J. J. Thomson 33 ; Rntherford .5; Perrin .026.

It will be seen that hard rays show a closer agreement than soft rays with the density law which holds for the $\gamma$ rays of radium. It is probable that a still harder bulb would further reduce the value obtained for methyl iodide. By interposing an additional lead screen it was shown that the value obtained depended more on the hardness of the bulb than on the amount of lead penetrated. This has been proved more directly by McClung ("Nature,' 17th March, 1904), who has obtained lower ionization values, except in the case of hydrogen, by increasing the hardness of the bulb employed.

The curves for pressure and current are shown in fig. 3 , for air, $\mathrm{H}_{2} \mathrm{~S}$, and $\mathrm{H}$. Their curvature indicates a considerable amount of secondary radiation; this will be considered later. The portion of the curve between 18 and $50 \mathrm{mms}$. was found to be a straight line (fig. 4), and the readings for the gases used were taken between these limits. The value for hydrogen relative to air seemed to be constant for all pressures. The curve for $\mathrm{H}_{2} \mathrm{~S}$ intersected the curve for air. The scale of the diagram is too small to show this, but the values obtained were:

$\begin{array}{cc}\text { Pressure in mms. } & \text { Valne relative to air. } \\ 760 & 1.45 \\ 218 & 1.36 \\ 63 & 1.05 \\ 50 & .90\end{array}$

$\gamma$ Rays of Radium.

Observations were made in a manner similar to those for Röntgen rays. The current-pressure curve between 30 and 
614 Mr. A. S. Eve on the Ionization product in

Fig. 3.

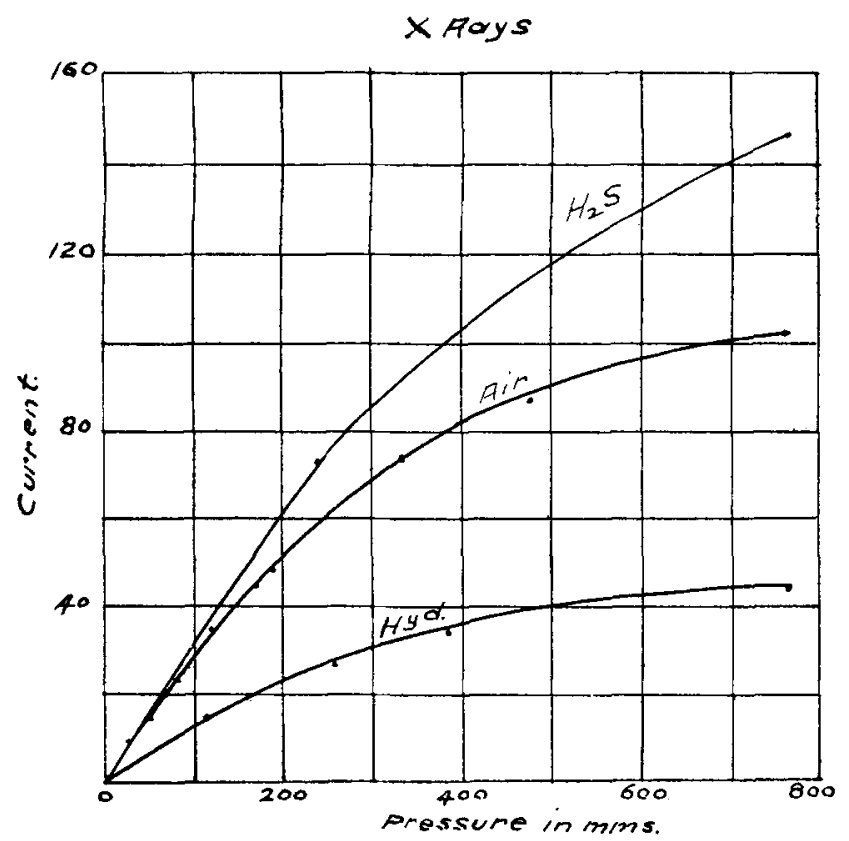

Fig. 4.

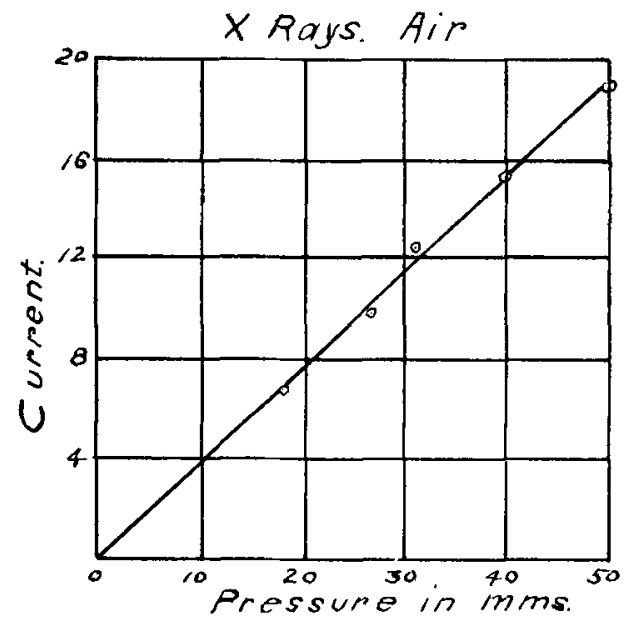


Gases by penetrating Röntgen and Radium Rays. $\quad 615$

$760 \mathrm{mms}$. was found to be a straight line (fig. 5). The values obtained were practically the same as those given by Strutt, Proc. Roy. Soc. 5th Aug. 1903.

Fig. 5.

YAays. Air.

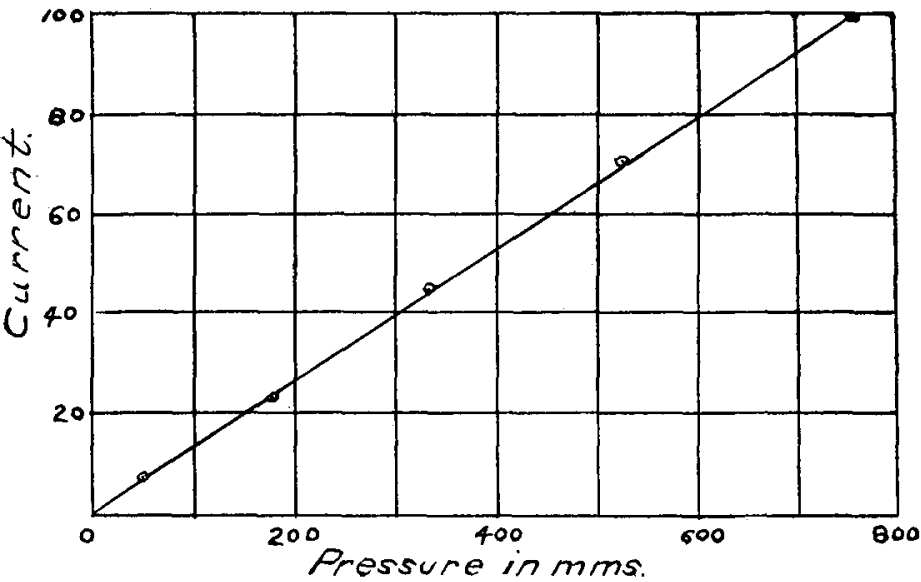

\begin{tabular}{|c|c|c|c|}
\hline Gas. & Density. & Strutt. & $\begin{array}{c}\text { Present } \\
\text { Experiments. }\end{array}$ \\
\hline $\mathrm{H}$ & .07 & $\cdot 17$ & $\cdot 19$ \\
\hline Air ......... & $1 \cdot 0$ & $1 \cdot 0$ & $1 \cdot 0$ \\
\hline 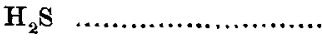 & $1 \cdot 2$ & $\cdots$ & $1 \cdot 23$ \\
\hline Chioroform ........ & $4 \cdot 32$ & $4 \cdot 88$ & $4 \cdot 8$ \\
\hline Methyl Iodide ................. & $5 \cdot 31$ & $5 \cdot 67$ & $5 \cdot 6$ \\
\hline Carbon Tetrachloride .. & $5 \cdot 05$ & $4 \cdot 80$ & $5 \cdot 2$ \\
\hline
\end{tabular}

Secondary Radiation.

With the Röntgen rays there was abundant evidence of secondary and tertiary radiation. The block of lead and the large and small lead covers effectively screened the upper electroscopes. The amount of secondary radiation in the lower brass cylinders was proved to be large. A sheet of cardboard painted with phosphoric acid reduced the current from 100 to 40 , two sheets from 100 to 26 . The cardboard appeared to be an unsatisfactory conductor, and the interior of the brass cylinder was therefore coated with sheet 
aluminium 85 mms. thick. This reduced the ionizationourrent from 100 to 22 , and a screen of double thickness to 20.6. The electroscope was then filled with air and various gases, and the observations were repeated. As the deflexions of the leaves were only about a quarter of their former value, it was necessary to run the bulb for a considerable time. The results were not as accurate as in the first instance. Although 78 per cent. of the rays had been cut off, the values obtained agreed with those previously determined. There cannot be any wide divergence between the relative conductivities for primary and secondary rays. In the case of the secondary radiation caused by the rays, the interior aluminium screen of $\cdot 85 \mathrm{mms}$. thickness reduced the ionizationcurrent from 100 to 79 , and a double thickness from 100 to 70 . These screens had a negligible effect if placed on the outside of the electroscope. The absorption coefficients may therefore be calculated on the assumption that the primary rays are unaffected. If $I_{0}$ be the initial intensity, and $I_{t}$ be the intensity after penetration through thickness $t$, then $\lambda$ the coefficient of absorption may be calculated from the equation $\mathrm{I}_{t}=\mathrm{I}_{0} e^{-\lambda t}$.

The values of $\lambda$ for secondary rays from lead penetrating aluminium were found to be

Sècondary $\gamma$ rays $\ldots \ldots \ldots \ldots . .10$

Secondary Röntgen rays...... 47

The former were therefore about five times as penetrating as the latter.

The curves in fig. 3 indicate that secondary Röntgen rays are absorbed in a few centimetres of air, except at low pressures, whilst the straight line in fig. 5 .shows that the $\gamma$ rays pass the air with little absorption. This agrees with Becquerel's results obtained by photographic methods.

By interposing lead screens outside the electroscope the penetrating powers of the primary rays were also compared. The values of $\lambda$ for lead with Röntgen rays were $24^{\cdot} 6$ for the first $1.7 \mathrm{mms}$. and 21.0 for the thickness 1.7 to 3.4 . There is a similar decrease in the value of $\lambda$ for lead with $\gamma$ rays from $\cdot 64$ to $\cdot 47$, as the thickness ranges from 2 to $96 \mathrm{mms}$. Taking mean values, it may be said that $\gamma$ rays are about 40 times as penetrating as the Röntgen rays used.

Whilst these experiments have been in progress, papers have appeared in the Annalen der Physik (Nos. 6, 7, 1904) by F. Paschen. In the first he describes the repetition, with $\gamma$ rays, of the experiments made by Strutt in the case of $\beta$ rays (Phil. Mag. 1903, [6] vi. p. 538). 
On the other hand, J. J. Thomson, using a thicker lead case round the radium employed, failed to obtain any such results (Soddy, Radioactivity, p. 181). McClelland's observations by other methods also indicate that the $\gamma$ rays do not carry a charge (Phil. Mag. July 1904).

Paschen, in his second paper, adds further indirect evidence of the view that the rays are projected particles with a negative charge.

Since this paper was forwarded to England, the writer has made some further experiments, which form the subject matter of a future communication.

It may be convenient to give a brief summary :-

(1) An endeavour to deflect the $\gamma$ rays in a very powerful magnetic field has failed to show any curvature of the rays.

(2) The $\beta$ rays can be deflected entirely away from the $\gamma$ rays, so that the two classes of rays belong to different types.

(3) . If radium is enclosed in a mass of lead, several centimetres thick, negatively charged particles are projected from the outer layers of the lead; these can be readily deviated in a magnetic field and are absorbed by one or two millimetres of lead, whereas the $\gamma$ rays will penetrate several centimetres. Thus the $\gamma$ rays give rise to secondary radiation of the cathode type, and it is these rays which Paschen has detected and which he incorrectly concluded to be $\gamma$ rays.

Direct experiments by Becquerel, Rutherford, and Villard have failed to detect any deflexion of the $\gamma$ rays in a powerful magnetic field.

The theoretical aspect of the case is summarized by Rutherford in ' Nature,' 10th March, 1904 :-

"As a result of the sudden expulsion of the $\beta$ particle from radium, it is to be expected that a narrow electromagnetic pulse, i. e. a ' hard' or penetrating type of Röntgen rays would be generated. In addition, on account of the great speed of the $\beta$ particle, it is able to penetrate through a considerable thickness of matter before it is stopped. A broad pulse or 'soft' Röntgen ray should thus arise at the point of incidence of the $\beta$ rays."

It has been pointed out that the $\gamma$ rays arise at the time of the expulsion of the $\beta$ ray and not by the bombardment of the radium itself, since the amount of $\gamma$ rays from radium is independent of its degree of concentration.

From the present theoretical view that Röntgen rays are pulses, it follows that a type of Röntgen rays should be produced by the $\beta$ ray, and from other evidence we should expect these to be of a very penetrating character. 
'The evidence that $\gamma$ rays are Röntgen rays is two-fold :-

(1) The $\gamma$ rays are not deflected by a magnetic field.

(2) In the changes of radium the $\beta$ and $\gamma$ rays always appear together and in the same proportion. This result is to be expected if the $\gamma$ rays are produced by the $\beta$.

In any case the present paper removes an objection to this view. It is true that methyl iodide remains as a marked exception to the density law, but it is probable that harder rays than those employed would bring this vapour into line with others.

In conclusion, I have to thank Professor Rutherford for suggesting the experiment, and for his encouragement and advice in carrying it out.

McGill University, Montreal, July 1904.

LXI. Notes on the Radioactivity of Various Materials. By Hon. R. J. Strute, Fellow of Trinity College, Cambridge*. TN this note I shall put together some rather fragmentary observations on the presence of radium in various materials. The note may be regarded as supplementary to a paper published in the Proc. Roy. Soc. Ixxiii. p. 192.

The method of experimenting was the same as is described in that paper. The emanation was extracted from the substance by heat, and introduced into an electroscope: the rate of leak was read in the usual way.

The following Table (p. 619) gives the results for the various materials, on the same scale as in the former paper. These were not, for the most part, carried out more than once; and must not be regarded as much more than indications.

1. This refers to a hard deposit, left in the lead pipes of the ancient Roman baths. It contains less iron than the modern deposits, and is much less radioactive. It would be rash to draw any positive conclusion from the latter fact, for we are ignorant of the precise conditions under which the Roman deposits were formed. But the idea suggests itself that the radium has been here separated for 2000 years from its parent (uranium?), and is consequently much diminished in activity. I have tested the most active of the modern deposits, but found no uranium in 100 grams of it. One milligram should have been easily detected.

2-5. Lord Blythswood and Mr. Allen have found the gas of the Bath springs to contain emanation. I wished to compare the activity of this gas with that of the other materials, 